\title{
Kvinnor som injicerar heroin respektive amfetamin. - Skillnader i social situation, erfarenhet av behandling och önskemål om hjälp
}

\author{
TORKEL RICHERT, SVEN-AXEL MÅNSSON \&
}

LEILI LAANEMETS

Injektionsmissbrukande kvinnor är en extra utsatt grupp som kan förväntas ha särskilda behov vad gäller vård och behand-

ling. I föreliggande studie jämförs injektionsmissbrukande kvinnor med heroin respektive amfetamin som huvudsaklig drog avseende deras sociala situation, myndighetskontakter, tidigare erfarenhet av behandling samt aktuella önskemål om hjälp.

\section{Inledning}

\section{Injektionsmissbrukande kvinnor, en särskilt utsatt grupp}

Injektionsmissbrukare är i flera avseenden

Torkel Richert, adjunkt och doktorand i socialt arbete vid Fakulteten för Hälsa och samhälle, Malmö högskola.

Sven-Axel Månsson, professor i socialt arbete vid Fakulteten för Hälsa och samhälle, Malmö högskola. Leili Laanemets, fil. dr. i socialt arbete och lektor vid Fakulteten för Hälsa och samhälle, Malmö högskola. en särskilt utsatt grupp med högre sjuklighet och dödlighet i jämförelse både med befolkningen i stort och med andra narkotikamissbrukare (Pates m.fl. 2005). Hos hela populationen intravenösa missbrukare, som i Sverige domineras av individer med amfetamin som huvuddrog, finner man en femfaldig förhöjning av dödligheten. Dödligheten hos obehandlade heroinmissbrukare har beräknats till uppåt 60 gånger högre än hos matchande individer i normalbefolkningen (Socialstyrelsen 2004, Heilig 2004). Även om injektionsmissbrukare inte utgör en homogen grupp (Stenström 2008), 
visar studier att injektionsmissbrukare på många sätt faller ut som kraftigt marginaliserade med en omfattande och långvarig social, psykisk och ekonomisk problematik (EMCDDA 2001, ECNN 2002, Lander m.fl. 2002).

Injektionsmissbrukande kvinnor har i flera avseenden en än mer problematisk situation. Kvinnor är generellt yngre än män vid narkotikadebuten och deras progression mot ett tyngre och regelbundet missbruk sker snabbare (Angelin m.fl. 1987, Bergmark m.fl. 1994, Byqvist 1997, Tunving 1986, Stenström 2008). De förefaller överlag också vara mer marginaliserade och socialt utslagna (Stenström \& Örnberg 1995) och ha en sämre arbetsmarknadsanknytning jämfört med injektionsmissbrukande män (Olsson m.fl. 2001, Stenström 2008, Bretteville-Jensen 2005).

Studier har också visat på hur missbrukande kvinnors situation skiljer sig från männens på grund av graviditeter, moderskap och ett större familjeansvar (Rosenbaum 1982, Lander 2003, Trulsson 2003) samt hur prostitution, som är vanligt bland injektionsmissbrukande kvinnor, innebär en stor risk för våld och övergrepp (Dalla m.fl. 2003, Bourgois m.fl. 2004, Kurtz m.fl. 2004, Holmberg m.fl. 2005 ), ökad nivå av depression och ångest (Paone m.fl. 1995, 1999) samt barriärer för att söka sig till behandling (Kurtz m.fl. 2005, Weiner 1996).

Vi vet således en del om skillnader mellan injektionsmissbrukare och narkotikaanvändare som inte injicerar och om skillnader mellan män och kvinnor som injicerar narkotika. Mindre är känt om eventuella skillnader beroende på vilken drog individen huvudsakligen injicerar.

\section{Injektionsmissbruk av heroin och amfetamin}

Endast ett fåtal studier har jämfört missbruksförlopp, social situation eller vårdbehov för injektionsmissbrukare med heroin respektive amfetamin som huvudsaklig drog. Injektionsmissbrukare med heroin som huvuddrog har i flera avseenden visat sig ha en större problematik. De tydligaste skillnaderna har att göra med drogbruk och grad av beroende, där heroinanvändare har visat sig ha ett mer varaktigt missbruk och betydligt färre perioder med ett mindre omfattande drogbruk (Hser m.fl. 2008), ett mer frekvent bruk (Darke \& Hall 1995) samt högre grad av beroende (Gossop m.fl. 1992, Anthony m.fl. 1994, Darke \& Hall 1995). Andra faktorer som i större utsträckning visat sig vara förknippade med ett heroinmissbruk är kriminellt beteende (Darke \& Hall 1995, Hall m.fl. 1993), illegala inkomstkällor och erfarenhet av prostitution (Bretteville-Jensen 2005, Richert 2009, Bergmark m.fl. 1994) samt social marginalisering (Stenström \& Öberg 1995).

Vissa studier har dock visat att det framförallt finns stora likheter i konsekvenser av injektionsmissbruk, oavsett om det är heroin eller amfetamin som injiceras. I en studie som jämför skadeverkningar associerade med heroin respektive amfetamin, Kaye \& Darke (2000), uppvisade heroinanvändarna visserligen en högre grad av beroende och ett mer kriminellt beteende men inga signifikanta skillnader mellan de två grupperna kunde påvisas vad gäller allmänt hälsotillstånd, psykologisk funktionalitet eller riskbeteende vid injicering. 
Detta trots att amfetaminanvändarna generellt var yngre och hade ett mindre frekvent drogbruk. Författarna menar därför att amfetaminmissbruk i vissa avseenden bör betraktas som minst lika skadligt som heroinmissbruk (Kaye \& Darke 2000). Även Håkanssons avhandling (2009) kring personer med ett tungt narkotikamissbruk inom svensk kriminalvård visar framförallt på stora likheter i problematik mellan heroinoch amfetaminanvändare, även om amfetaminanvändarna hade en något högre grad av problematisk alkoholkonsumtion det senaste året, samt i något större utsträckning uppvisade psykiatriska symptom och kognitiva problem. Utifrån dessa resultat drar Håkansson slutsatsen att amfetaminanvändare borde ha hälsoproblem och behov av vård och behandling åtminstone jämförbara med heroinanvändare (Håkansson 2009).

\section{Behandlingsinsatser för heroin-och amfetaminberoende}

Vad gäller jämförelser av behandlingsinsatser för amfetamin- respektive heroinmissbruk finns liten kunskap nationellt (Håkansson 2009). Internationell forskning har visat att behandlingsalternativ för amfetaminmissbrukare är få i jämförelse med dem som finns tillgängliga för heroinmissbrukare och att färre amfetaminmissbrukare erbjuds behandling (se t.ex. McKetin m.fl. 2005, Hall m.fl. 1993). Trots att kunskap finns om stora skador förknippade med amfetaminmissbruk saknas idag specifik medicinsk behandling, både för amfeta- minabstinens (Srisurapanont m.fl. 2001a) och för amfetaminberoende (Srisurapanont m.fl. 2001b).

Håkanssons studie (2009) visar att amfetaminanvändare i jämförelse med heroinanvändare $\mathrm{i}$ betydligt mindre utsträckning varit $\mathrm{i}$ inneliggande avgiftning och att de även i något mindre utsträckning deltagit i institutionsvård. Resultatet pekar också på att amfetaminanvändares vårdbehov i vissa fall möts med fängelse i stället för missbruksbehandling. Håkansson menar att mycket tyder på att amfetaminanvändare $i$ Sverige generellt deltagit $i$ vård $i$ mindre utsträckning än heroinanvändare samt att de i mindre utsträckning söker sig till behandling. Då kunskapen kring skillnader i erfarenhet av behandling för amfetamin- respektive heroinmissbruk är mycket begränsade finns ett stort behov av studier kring detta (Håkansson 2009).

\section{Studiens syfte}

Att undersöka behandlingserfarenhet och önskemål om hjälp bland kvinnor som injicerar heroin eller amfetamin är viktigt i flera avseenden. Mycket tyder på att injektionsmissbrukande kvinnor är en särskilt utsatt grupp i samhället, vilka kan förväntas ha särskilda behov vad gäller vård och behandling. Trots detta vet vi lite om deras sociala situation eller önskemål om hjälp. Det saknas också till stor del nationell kunskap om eventuella skillnader mellan injektionsmissbrukare med heroin respektive amfetamin som huvudsaklig drog, trots att dessa två droger dominerar bland tunga missbrukare i Sverige. Ingen tidigare studie 
har undersökt huruvida dessa två grupper skiljer sig åt vad gäller social situation eller önskemål om hjälp.

Syftet med denna studie är att jämföra injektionsmissbrukande kvinnor på sprutbytesprogrammet i Malmö med heroin respektive amfetamin som huvudsaklig drog avseende deras sociala situation, kontakter med myndigheter, tidigare erfarenhet av behandling samt aktuella önskemål om hjälp.

\section{Metod och material}

Materialet i studien bygger på strukturerade intervjuer med kvinnor på sprutbytesprogrammet i Malmö. Till sprutbytesprogrammet kommer personer som injicerar narkotika, för att hämta rena sprutor och kanyler. Besökarna kommer framförallt från Malmö, men även från andra orter i närområdet. Till programmet kommer varje år ca 1100 besökare varav ca 200 är nybesök (Registerdata från 2005). ${ }^{1}$ Verksamheten är, tillsammans med Sprutbytesprogrammet i Lund, unik i Sverige med sin breda kontaktyta till individer med ett pågående narkotikamissbruk.

Andelen kvinnor i sprutbytesprogrammet har under alla år legat kring 25 procent (Registerdata från sprutbytesprogrammet) vilket stämmer väl med andra studier av tunga missbrukare både nationellt (Olsson m.fl. 2001; CAN 2006) och internationellt (Aceijas m.fl. 2006). Vid programmets start 1989 var amfetamin den klart dominerande drogen bland besökarna. Sedan

1 Data hämtade från sprutbytesprogrammets egen statistik (samma år som datainsamlingen). dess har andelen som använder heroin ökat samtidigt som andelen som använder amfetamin har minskat (Stenström 2008). År 2005 var skillnaden i princip utjämnad. Då uppgav 44 procent av besökarna (50 \% av kvinnorna) heroin som sin huvudsakliga drog (Registerdata från 2005).

Besökarna utgörs generellt av en grupp erfarna missbrukare som har en lång missbrukarkarriär bakom sig. Den genomsnittlige sprutbytaren har använt narkotika under 23 år varav drogerna injicerats under knappt 16 år. Omfattningen och intensiteten $\mathrm{i}$ injektionsmissbruket varierar stort från person till person och över tid. Det vanliga är att ha injicerat periodvis (49\%) eller regelbundet (38\%), ett fåtal av besökarna (13\%) har uppgivit att de endast injicerat någon eller några gånger. En större andel av heroinanvändarna har ett regelbundet injektionsmissbruk i jämförelse med amfetaminanvändarna. I genomsnitt nyttjar cirka 70 procent av besökarna sin huvuddrog dagligen eller så gott som dagligen. Kvinnorna uppger att de använder sin huvuddrog något oftare än männen (Stenström 2008).

De kvinnliga sprutbytarna verkar i flera avseenden ha en mer problematisk situation än de manliga. I förhållande till männen har kvinnorna både ett mer omfattande missbruk och allvarligare sociala, fysiska samt psykiska konsekvenser av sitt missbruk. Kvinnornas upplevelser av socialt utanförskap är också större (Stenström 2008).

\section{Datainsamlingochanalys}

Vår undersökning startade i juli 2005 och pågick fram till oktober 2006. Samtliga

Richert, Månsson \& Laanemets: Kvinnor som injicerar heroin respektive amfetamin. 
kvinnliga patienter som besökte sprutbytesprogrammet under denna period tillfrågades om deltagande och vid samma tillfälle fick de även en kortare informationsbroschyr om studien. Vid kvinnans nästa besök, eller när det bedömdes vara lämpligt utifrån kvinnans situation och utrymme i verksamheten, genomfördes intervjun. Intervjuerna tog cirka 15-30 minuter i anspråk.

Intervjuerna genomfördes av personalen på sprutbytesprogrammet vilket innebar att den direkta kontakten med kvinnorna enbart kom att utgöras av för dem kända personer. Personalen som genomförde intervjuerna har arbetat länge på mottagningen och har ett mycket gott anseende bland besökarna. ${ }^{2}$ Detta bedömde vi vara av stor betydelse på grund av känsligheten i vissa av de efterfrågade uppgifterna.

Under intervjun ställdes frågor kring ålder, boendesituation, huvudsaklig drog, ${ }^{3}$ anskaffning av droger, finansiering av droginköp, erfarenhet av prostitution, utsatt-

2 Personalens goda anseende bland besökarna har tydligt framgått under en av författarnas intervjuer med ett stort antal kvinnor på sprutbytesprogrammet. Även andra forskare har bekräftat detta utifrån sina möten med deltagare på sprutbytesprogrammet se t.ex. Svensson och Kristiansen (2004).

3 Många kvinnor använder flera olika preparat utöver den drog som de definierar som sin huvudsakliga drog. Heroin- och amfetaminanvändare har dock visat sig vara relativt separerade grupper i Sverige med liten överlappning vad gäller dessa två droger (Håkansson 2009). Fortsättningsvis kommer även termerna heroinanvändare respektive amfetaminanvändare att användas för att skilja de två grupperna åt. het för våld, kontakt med myndigheter och organisationer samt erfarenhet av behandling för missbruk. Samtliga frågor försågs med fasta svarsalternativ. Dessa frågeområden valdes för att ge en översiktlig bild av kvinnornas situation. Eftersom det ur genomförbarhetssynpunkt ansågs viktigt att hålla enkäten kort, då flertalet besökare är inne i ett aktivt missbruk och sällan har tid, ork eller vilja att ställa upp på längre intervjuer, har antalet frågor begränsats. Detta har inneburit att frågor kring omfattning och längd i missbruk, familjesituation och utbildningsnivå har utelämnats.

Avslutningsvis tillfrågades kvinnorna också om de önskade någon hjälp från samhället för att förändra sin situation. De kvinnor som inte önskade hjälp fick en följdfråga om anledningen till detta och de kvinnor som önskade hjälp ombads beskriva vilken typ av hjälp de önskade. På dessa frågor fick kvinnorna med egna ord formulera sina svar. Svaren har kategoriserats i centrala teman.

Datamaterialet har kodats och lagts in i statistikprogrammet SPSS för bearbetning och analys. Trots att studien är att betrakta som en totalundersökning (studiens målgrupp utgör samtliga kvinnor på sprutbytesprogrammet under ett drygt år) har vi valt att genomföra och tolka signifikanstester. Detta för att få en indikation på hur robusta skillnaderna är mellan de två undersökta grupperna. Pearson's Chitvåtest samt Fisher's Exact Test (för de fall där antalet observationer är lågt) har använts för signifikansprövning. P- värden $<0,05$ har bedömts som statistiskt signifikanta. I ett andra steg har logistisk regression använts för att undersöka huruvida andra faktorer 
än huvuddrog har betydelse för önskemål om hjälp samt för att undersöka om skillnader i önskemål om hjälp mellan kvinnor med heroin respektive amfetamin som huvudsaklig drog kvarstår efter kontroll för boendesituation, typ av inkomstkällor samt erfarenhet av att sälja sex.

\section{Undersökningsgruppen}

Studiens målgrupp är samtliga kvinnliga besökare på sprutbytesprogrammet i Malmö under ett drygt år. Totalt besökte 231 kvinnor sprutbytesprogrammet under insamlingsperioden, varav 188 intervjuades av personalen. Att de övriga 43 kvinnorna inte intervjuades berodde framförallt på att de hade för få besök under intervjuperioden (intervjun genomfördes ofta vid andra eller tredje besöket). Sju av de kvinnor som var aktuella under insamlingsperioden påbörjade behandling och avbröt sin kontakt med sprutbytet innan intervjun hade genomförts. Andra orsaker till uteblivna intervjuer var att besökares psykiska tillstånd bedömdes vara av den arten att intervju inte gick att genomföra (två kvinnor) samt dödsfall under intervjuperioden (två kvinnor). Då endast data kring ålder och huvudsaklig drog finns tillgänglig för bortfallsgruppen har det inte varit möjligt att genomföra någon avancerad bortfallsanalys. Vad gäller dessa två variabler fanns dock inga avgörande skillnader mellan de två grupperna. Stenströms (2008) studie kring sprutbytesbesökarna visade att "drop in besökarna/de sporadiska besökarna" (de som endast besökt verksamheten max 2 gånger per år), i viss mån skiljer sig från övriga besökare genom en högre subkulturell involvering. ${ }^{4}$ Intervjuarnas bedömning är dock att bortfallsgruppen i föreliggande studie inte väsentligt skiljer sig från den intervjuade gruppen.

Av de totalt 188 intervjuade kvinnorna uppgav 99 heroin och 88 amfetamin som sin huvudsakliga drog. En informant avstod från att uppge huvudsaklig drog och har därför exkluderats i analysen.

Åldern i gruppen sträckte sig mellan 20 och 66 år, med en medelålder för hela gruppen på 38 år. Medelåldern för dem med heroin som huvudsaklig drog var 34 år och för dem med amfetamin som huvudsaklig drog 42 år.

\section{Studiens begränsningaroch vetenskapliga värde}

Då informanterna utgör den stora majoriteten av de kvinnor som besökt sprutbytesprogrammet under ett år och då inget tyder på att bortfallsgruppen (43 kvinnor) väsentligt skulle skilja sig från de intervjuade, bör resultatet i hög grad vara generaliserbart till hela populationen kvinnliga sprutbytare i Malmö. Även om studien är en totalundersökning kan det finnas skäl att diskutera resultatets eventuella giltighet för en vidare grupp än den undersökta. Eftersom informanterna utgör en stor andel

4 Indikatorer på en hög grad av subkulturell involvering är t.ex. kontakter med polis, kronofogde och socialtjänst, att ha varit föremål för tvångsvård för missbruk, att ha blivit förhörd p.g.a. brottsmisstanke, att ha blivit dömd för brott, att ha avtjänat fängelsestraff.

Richert, Månsson \& Laanemets: Kvinnor som injicerar heroin respektive amfetamin. 
av Skånes kvinnor med ett tungt missbruk borde resultatet i viss mån även vara giltigt för denna större grupp. Den senaste kartläggningen av tunga missbrukare i Skåne (Stafström \& Norén 2005) beräknade andelen till drygt 1100 i Malmö kommun och ca 3000 i Skåne län totalt. Då andelen kvinnor bland tunga missbrukare ligger kring 25 procent skulle detta innebära ca 275350 tungt missbrukande kvinnor i Malmö kommun och ca 750 i Skåne län. Informanterna skulle i så fall utgöra cirka hälften av Malmös och cirka en fjärdedel av Skåne läns kvinnor med ett tungt missbruk. ${ }^{5}$

Generaliseringar av resultatet till grupper utanför sprutbytespopulationen bör dock ske med försiktighet. Sprutbytarna har generellt visat sig ha en högre medelålder i jämförelse med tunga missbrukare $i$ landet i stort och i jämförelse med övriga tunga missbrukare i Malmö i synnerhet. En andra skillnad har att göra med försörjning av missbruket. I jämförelse med övriga tunga missbrukare i Malmö finansierade sprutbytarna i större utsträckning sina narkotikainköp med legala inkomster. En tredje skillnad är att sprutbytarna i större utsträckning än övriga tunga missbrukare i de tre storstäderna injicerar i perioder snarare än regelbundet (Olsson m.fl. 2001). ${ }^{6}$

Dessa tre skillnader kan troligen till stor del förklaras av det faktum att per-

5 Då en tidigare kartläggning (Olsson m.fl. 2001), vilken även uppskattade och adderade ett mörkertal, beräknade antalet något högre, bör siffrorna dock ses med en viss försiktighet.

6 Då Olssons studie bygger på socialarbetares skattningar av missbrukarens situation bör resultaten ses med viss försiktighet. soner med amfetamin som huvuddrog är överrepresenterade bland sprutbytarna. ${ }^{7}$ Detta då amfetaminanvändare i jämförelse med heroinanvändare tidigare visat sig ha en högre genomsnittlig ålder (Lander m.fl. 2002), ${ }^{8}$ större del legala inkomster (Bretteville-Jensen 2005) samt ett mer periodiskt injektionsbruk (Stenström 2008). Flera av de skillnader mellan sprutbytare och övriga tunga missbrukare som dokumenterats verkar således ha att göra med vilken huvuddrog som dominerar i gruppen.

En begränsning i studien har att göra med materialets omfattning. Det faktum att undersökningsgruppen är relativt liten $(\mathrm{N}=187)$, innebär begränsningar vad gäller möjliga analysmodeller. Den jämna fördelningen mellan kvinnor med heroin- respektive amfetamin som huvudsaklig drog (99 respektive 88) har dock inneburit goda möjligheter till jämförelser dessa grupper emellan.

En annan möjlig svaghet har att göra med osäkerheten kring intervjusvarens trovär-

7 Olsson m.fl. (2001) har visat att sprutbytarna i jämförelse med andra tunga missbrukare i de tre storstäderna i betydligt större utsträckning uppgivit amfetamin som huvudsaklig drog. Skillnaden mellan sprutbytare och icke sprutbytare var signifikant (Mann- Whitney U-test; $\mathrm{p}<0,001)$.

8 Andra möjliga förklaringar till åldersskillnaden mellan sprutbytarna och övriga tunga missbrukare, vilka Stenström (2008) tidigare framfört, skulle kunna vara sprutbytesprogrammets minimiålder 20 år, och det faktum att definitionen "tunga missbrukare" inkluderar en mindre grupp som inte injicerar och vilken troligen har en yngre medelålder än sprutbytarna då injektionsdebuten vanligtvis sker 4-5 år efter drogdebuten (Rönnberg m.fl. 1992). 
dighet. Flera av intervjufrågorna i studien har att göra med känsliga ämnen som försörjning genom kriminella aktiviteter (langning, stölder) eller starkt stigmatiserade handlingar (t.ex. prostitution), vilket skulle kunna innebära en ökad risk för bortfall eller viss underrapportering kring dessa frågor. Personalens täta och långvariga kontakt med besökarna och icke dömande förhållningssätt borde dock öka möjligheten för förtroende och för ärliga svar. Möjligen bör man trots allt tolka de frekvenser som har att göra med illegala eller stigmatiserande handlingar som minimital, dvs. det reella antalet skulle kunna antas vara något högre. Då syftet här främst är att jämföra två grupper bör detta inte vara ett avgörande problem, då en eventuell underrapportering bör gälla båda grupperna.

\section{Resultat}

\section{Kvinnornas sociala situation}

De centrala resultaten kring kvinnornas sociala situation redovisas i tabell ett nedan. De områden som tas upp är boende, inkomstkälla, förekomst av prostitution samt utsatthet för våld i samband med sexsäljande.

Vad gäller bostadssituation kunde inga större skillnader konstateras utifrån huvudsaklig drog. I båda grupperna uppgav drygt hälften av kvinnorna att de vid intervjutillfället bodde i egen lägenhet och en fjärdedel att de bodde inneboende eller i andra hand. En mindre andel kvinnor bodde vid intervjutillfället i något av socialtjänstens boenden, på härbärge eller saknade helt bostad. Kvinnor med amfetamin som huvudsaklig drog uppgav i större utsträckning att de bodde på härbärge eller helt saknade bostad medan en större andel heroinanvändare uppgav att de bodde i något av socialtjänstens boenden.

Kvinnornas sätt att finansiera sina droginköp har delvis redovisats i en tidigare artikel (se Richert 2009). Det föreligger stora skillnader i försörjningssätt beroende på vilken drog kvinnorna huvudsakligen använder. En större andel heroinanvändare uppgav flera olika inkomstkällor, inkomst genom socialbidrag, stölder, langning samt prostitution medan en större andel amfetaminanvändare uppgav inkomster från lönearbete eller pension. Majoriteten av amfetaminanvändarna, 63 procent, uppgav endast legala inkomstkällor. Motsvarande andel för de kvinnor med heroin som huvudsaklig drog var 25 procent.

En vidare analys visade också på samband mellan bostadssituation och typ av inkomstkällor vilka såg olika ut för heroinrespektive amfetaminanvändare.

Av de kvinnor som endast har uppgivit legala inkomster har majoriteten, 63 procent, också uppgivit att de bor i egen bostad. Motsvarande andel bland dem med både legala och illegala inkomster var 51 procent och för dem med endast illegala inkomster 17 procent. De kvinnor som endast uppgav illegala inkomster var också de som i störst utsträckning helt saknade bostad. En större andel amfetaminanvändare (40\% mot $15 \%$ ) har både egen bostad och uteslutande legala/formella inkomster medan en större andel heroinanvändare (14\% mot 7 \%) har en osäker bostadssitua-

Richert, Månsson \& Laanemets: Kvinnor som injicerar heroin respektive amfetamin. 
tion i kombination med illegala/informella inkomstkällor som langning, prostitution eller stölder.

Det förelåg tydliga skillnader vad gäller erfarenhet av att sälja sex, bero- ende på huvudsaklig drog. Kvinnor med heroin som huvudsaklig drog hade i större utsträckning någon gång sålt sex. Av kvinnorna med erfarenhet av att sälja sex, hade heroinanvändarna också i större

\section{Tabell I}

Social situation. Fördelat efter huvudsaklig drog (Procent).

\begin{tabular}{|c|c|c|c|c|}
\hline & & Heroin & $\begin{array}{l}\text { Amfeta- } \\
\min \end{array}$ & Total \\
\hline \multirow[t]{5}{*}{ Boende } & & $N=99$ & $N=88$ & \\
\hline & Egen bostad & 56 & 52 & 54 \\
\hline & Inneboende/l andra hand & 25 & 26 & 26 \\
\hline & Socialtjänstens boende & 12 & 7 & 9 \\
\hline & Härberge/ Bostadslös & 7 & 15 & || \\
\hline \multirow{9}{*}{$\begin{array}{l}\text { Inkomstkälla } \\
\text { (de senaste } 14 \text { dagarna) }\end{array}$} & & $N=80$ & $N=76$ & \\
\hline & Lönearbete & $9 *$ & 21 & 15 \\
\hline & Pension & ||$* *$ & 31 & 21 \\
\hline & Socialbidrag & 51 & 39 & 45 \\
\hline & Stölder & $28 *$ & 14 & 21 \\
\hline & Langning & $33 * *$ & 13 & 23 \\
\hline & Prostitution & $38 * * *$ & 6 & 22 \\
\hline & Endast legala inkomster & $25 * * *$ & 63 & 43 \\
\hline & Flera olika inkomstkällor & $75 * *$ & 55 & 65 \\
\hline \multirow[t]{2}{*}{ Prostitution } & & $N=99$ & $N=88$ & \\
\hline & Sålt sex någon gång & $66^{* * * *}$ & 23 & 45 \\
\hline \multirow{2}{*}{$\begin{array}{l}\text { Utsatthet för våld i samband } \\
\text { med sexsäljande } \\
\text { (av dem som sålt sex) }\end{array}$} & & $N=66$ & $N=21$ & \\
\hline & Utsatt för våld & 55 & 67 & 56 \\
\hline
\end{tabular}

Signifikans: ${ }^{*} \mathrm{p}<0,05{ }^{* *} \mathrm{p}<0,01{ }^{* * *} \mathrm{p}<0,001$

I tabellerna anger $\mathrm{N}$ antalet heroin- respektive amfetaminanvändare som besvarat respektive fråga/tema i enkäten. Att $\mathrm{N}$ i vissa fall understiger det totala antalet respondenter ( 99 för heroinanvändare och 88 för amfetaminanvändare) beror antingen på att vissa kvinnor valt att inte svara på frågan (internt bortfall) eller på att de inte kunnat besvara frågan. Vad gäller utsatthet för våld i samband med sexsäljande är det t.ex. bara de kvinnor som någon gång sålt sex som har kunnat besvara frågan. 
utsträckning sålt sex det senaste året samt de senaste två veckorna. Majoriteten av kvinnorna var under 20 år första gången de sålde sex för att få pengar till droger. Amfetaminanvändarna debuterade generellt tidigare med att sälja sex i jämförelse med heroinanvändarna $(\mathrm{m}=$ 19,5 år mot m= 21,5 år).

En majoritet av de kvinnor som någon gång sålt sex, uppgav att de har blivit utsatta för våld i samband med att de sålt sex. Detta stämmer väl med vad den internationella forskningen på området tidigare visat (Dalla m.fl. 2003, Kurtz m.fl. 2004). De amfetaminanvändare som någon gång sålt sex, hade i större utsträckning varit utsatta för våld, i jämförelse med de heroinanvändare som någon gång sålt sex. Av de våldsutsatta kvinnorna hade 72 procent blivit utsatta för sexuellt tvång (kunden har tvingat till sig sexuell aktivitet), 90 procent blivit utsatta för fysiskt våld och 70 procent blivit utsatta för psykiskt våld.

\section{Myndighetskontakter och tidigare behandlingför missbruk}

Kvinnornas kontakter med myndigheter samt erfarenheter av behandling redovisas i tabell två.

Den övervägande majoriteten av kvinnorna har varit i kontakt med socialtjänsten det senaste året. Drygt hälften av kvinnorna har haft kontakt med ekonomiskt bistånd och en tredjedel med övrigt bistånd (övriga insatser, t.ex. missbruksbehandling). En relativt stor andel kvinnor (41 \%) har också haft kontakt med Beroendecen- trum under det senaste året. ${ }^{9}$ En betydligt större andel av heroinanvändarna har haft kontakt med de olika myndigheterna det senaste året.

En övervägande majoritet av kvinnorna med erfarenhet av att sälja sex har någon gång varit i kontakt med en organisation/ myndighet med anledning av denna erfarenhet. En större andel av de heroinanvändare som sålt sex hade haft kontakt med någon organisation/myndighet, kontakt med prostututionsgruppen, ${ }^{10}$ polisen, Navet, ${ }^{11}$ samt sjukvården medan en något större andel amfetaminanvändare med erfarenhet av att sälja sex hade haft kontakt med stadsmissionen. Den tydligaste

9 Beroendecentrum Malmö diagnostiserar, avgiftar och behandlar personer som är beroende av alkohol, narkotika och/eller läkemedel. På Beroendecentrum erbjuds läkemedelsassisterad behandling av långvarigt heroinmissbruk med metadon eller buprenorfin.

10 Prostitutionsgruppen riktar sig primärt till "gatuprostituerade" kvinnor i Malmö. Gruppen arbetar framförallt med uppsökande och kontaktskapande arbete, men även med stödjande, motiverande och behandlande samtal. En viktig uppgift är också att hjälpa kvinnorna till en kontakt med respektive stadsdelsförvaltning där de kan erbjudas någon form av bistånd $\mathrm{i}$ form av t.ex. försörjningsstöd, logi eller missbruksbehandling (Palmberg \& Lundberg 2009).

11 Navet är en öppenvårdsmottagning i Malmö, som vänder sig till heroinmissbrukande kvinnor involverade i prostitution. Verksamheten, som startade 2005, är ett samarbetsprojekt mellan beroendesjukvården och socialtjänsten. Viktiga mål med verksamheten är att underlätta för kvinnorna att komma in i underhållsbehandling samt ge dem möjlighet till en allsidig vård vilken utgår från deras specifika situation och behov (Laanemets 2007). 
skillnaden mellan de två grupperna är kontakten med Navet, en verksamhet endast tillgänglig för heroinanvändare.

Kvinnor med erfarenhet av att sälja sex hade, oavsett huvudsaklig drog, varit i behandling för sitt missbruk i större utsträckning än dem som saknade sådana erfarenheter $(\mathrm{p}<0.01)$.

Vad gäller erfarenhet av behandling framkom tydliga skillnader beroende

\section{Tabell 2}

Myndighetskontakter och erfarenhet av behandling. Fördelat efter huvudsaklig drog (Procent).

\begin{tabular}{|c|c|c|c|c|}
\hline & & Heroin & $\begin{array}{l}\text { Amfeta- } \\
\min \end{array}$ & Total \\
\hline \multirow{5}{*}{$\begin{array}{l}\text { Kontakt med myndighet det } \\
\text { senaste året }\end{array}$} & & $N=98$ & $N=88$ & \\
\hline & Socialtjänsten totalt & $84 * * *$ & 60 & 73 \\
\hline & Ekonomiskt bistånd & $66 * * *$ & 40 & 53 \\
\hline & Övrigt bistånd & $46 * * *$ & 19 & 33 \\
\hline & Beroendecentrum & $65 * * *$ & 13 & 41 \\
\hline \multirow{7}{*}{$\begin{array}{l}\text { Kontakt med myndighet med } \\
\text { anledning av sexsäljande (av } \\
\text { dem som sålt sex) }\end{array}$} & & $N=66$ & $N=21$ & \\
\hline & Någon myndighet & $85 *$ & 58 & 79 \\
\hline & Prostitutionsgruppen & 73 & 50 & 67 \\
\hline & Polisen & 41 & 25 & 37 \\
\hline & Navet & $33 *$ & 0 & 26 \\
\hline & Sjukvården & 24 & 15 & 22 \\
\hline & Stadsmissionen & 16 & 20 & 17 \\
\hline \multirow[t]{5}{*}{ Erfarenhet av behandling } & & $N=99$ & $N=88$ & \\
\hline & Behandlats någon gång & $94 * * *$ & 65 & 80 \\
\hline & Behandlats senaste året & $53 * * * *$ & 19 & 40 \\
\hline & Behandlats flera tillfällen & $80 * * * *$ & 41 & 61 \\
\hline & Behandlat sig själv & $95 * * * *$ & 52 & 74 \\
\hline \multirow{6}{*}{$\begin{array}{l}\text { Typ av behandling (av dem } \\
\text { som någon gång behandlats) }\end{array}$} & & $N=93$ & $N=56$ & \\
\hline & Behandlingshem & 86 & 76 & 82 \\
\hline & Öppenvård & $60 * *$ & 29 & 46 \\
\hline & Avgiftning & $91 * * * *$ & 59 & 78 \\
\hline & Läkemedelsassisterad beh. & $28 * * * *$ & 0 & 17 \\
\hline & LVM/LVU & 45 & 34 & 41 \\
\hline
\end{tabular}

Signifikans: ${ }^{*} \mathrm{p}<0,05{ }^{* *} \mathrm{p}<0,01{ }^{* * *} \mathrm{p}<0,001$ 
på huvudsaklig drog. En större andel kvinnor med heroin som huvuddrog har någon gång behandlats för sitt missbruk. En större andel av heroinanvändarna har också behandlats det senaste året, behandlats vid flera tillfällen, varit i läkemedelsassisterad behandling (metadon eller buprenorfin), behandlats i öppenvård samt avgiftats. Även erfarenhet av vård i behandlingshem samt vård enligt LVU/LVM var vanligare bland heroinanvändarna, även om skillnaderna härvidlag var små.

Kvinnorna tillfrågades också om de någon gång "behandlat sig själva" (självmedicinerat). Nästan samtliga heroinanvändare, 95 procent, och hälften av amfetaminanvändarna, 52 procent, svarade att de hade erfarenhet av självmedicinering. Av heroinanvändarna hade 71 procent någon gång självmedicinerat med Subutex (buprenorfin), 64 procent med metadon och 63 procent med bensodiazepiner. Av amfetaminanvändarna hade cirka hälften, 45 procent självmedicinerat med bensodiazipiner, 7 procent med subutex och 7 procent med metadon.

En femtedel av kvinnorna uppgav att de slutat använda sin huvuddrog, under en kortare eller längre period, utan att ta hjälp av andra droger, preparat eller läkemedel. Den stora majoriteten av dessa kvinnor (90 \%) var amfetaminanvändare.

\section{Önskemål om hjälpfrån samhället}

I tabell tre nedan redovisas i vilken utsträckning kvinnorna önskar hjälp från samhället och vilken typ av hjälp som framförallt efterfrågas.

Den stora majoriteten av kvinnorna, 68 procent, uppgav att de önskar någon typ av hjälp från samhället för att förändra sin situation. En betydligt större andel kvinnor med heroin som huvudsaklig drog uppgav att de önskade någon typ av hjälp (80\% mot $53 \%)$.

Av de heroinanvändare som inte önskade någon hjälp (20\%) uppgav det stora flertalet som anledning att de redan hade bra hjälp. Utifrån svaren från de amfetaminanvändare som uppgav att de inte önskade någon hjälp (47\%), kan tre huvudmotiv till detta urskiljas. En anledning är att man inte upplever sin situation eller sitt drogbruk som problematiskt, en annan att man vid behov själv kan förändra sin situation. Ett tredje vanligt skäl för att inte vilja ha hjälp är bristande tillit till att samhället kan ge rätt typ av hjälp. Endast ett fåtal amfetaminanvändare uppgav att de redan hade bra hjälp från samhället.

Vad gäller typ av hjälp som efterfrågas framkom vissa skillnader beroende på huvudsaklig drog. En större andel av heroinanvändarna önskade hjälp med behandling, boende, sysselsättning samt samtalskontakt. Vad gäller behandling var skillnaderna mellan de två grupperna särskilt tydliga. Kvinnor med amfetamin som huvudsaklig drog uppgav i större utsträckning att de önskade en större förståelse från samhället för deras situation eller en legalisering av narkotikabruk. Andra områden som flera kvinnor uttryckte önskemål om hjälp med var en bättre kontakt med sina barn, somatisk vård samt hjälp med ekonomin.

Richert, Månsson \& Laanemets: Kvinnor som injicerar heroin respektive amfetamin. 
En majoritet av de heroinanvändare som önskar någon behandlingsinsats uppgav att de önskar medicinsk behandling/underhållsbehandling med metadon eller subutex, en mindre andel önskar behandling i öppenvård eller på behandlingshem. Majoriteten av de amfetaminanvändare som önskar behandling har inte specificerat vilken typ av behandling de önskar. De som specificerat behandlingstyp önskar framförallt behandling i form av öppenvård eller behandlingshem/familjehem.

Den stora majoriteten av kvinnorna, 78 procent, anser att det är viktigt att det finns tillgång till behandlingsalternativ där endast kvinnor tas emot och 60 procent anser att Beroendecentrum bör öppna en särskild mottagning för kvinnor. En större andel heroinanvändare anser det vara viktigt med behandlingsalternativ där enbart kvinnor tas emot och en större andel heroinanvändare anser det vara viktigt att Bero- endecentrum öppnar en särskild mottagning för kvinnor.

Då kvinnornas önskemål om hjälp har varit av särskilt intresse har en fördjupad analys genomförts kring denna fråga. Logistisk regression har använts för att undersöka huruvida andra faktorer än huvuddrog har en betydelse för önskemål om hjälp, samt för att kontrollera om den signifikanta skillnaden i önskemål om hjälp som framkommit beroende på huvudsaklig drog, kvarstår efter kontroll för flera andra faktorer.

Tre analyssteg har genomförts. I ett första steg genomfördes ett antal enkla logistiska regressionsanalyser. Genom dessa undersöktes hur variablerna bostadssituation, typ av inkomst, prostitution samt ålder enskilt samvarierar med önskemål om hjälp. I ett andra steg genomfördes tre multivariata logistiska regressionsanalyser för att undersöka huruvida

\section{Tabell 3.}

Önskemål om hjälp. Fördelat efter huvudsaklig drog (Procent)

\begin{tabular}{llccc}
\hline & & Heroin & $\begin{array}{c}\text { Amfeta- } \\
\text { min }\end{array}$ & Total \\
\hline Vill du ha någon hälp? & Önskarhjälp & $\mathrm{N}=94$ & $\mathrm{~N}=77$ & \\
\hline Typ av hälp som önskas & & $80 * * *$ & 53 & 68 \\
\cline { 2 - 5 } & Behandling för missbruk & $\mathrm{N}=75$ & $\mathrm{~N}=41$ & \\
& Boende & 32 & 23 & 28 \\
& Sysselsättning & 15 & 8 & 12 \\
\cline { 2 - 5 } & Förståelse/Legalisering & $4 * * *$ & 17 & 10 \\
\cline { 2 - 5 } & Samtalskontakt/Psykiatri & 12 & 4 & 8 \\
& Annan typ av hiälp & 9 & 12 & 10 \\
\hline
\end{tabular}

Signifikans: ${ }^{*} \mathrm{p}<0,05{ }^{* *} \mathrm{p}<0,01{ }^{* * *} \mathrm{p}<0,001$ 
samband funna i modell ett kvarstår efter kontroll för huvudsaklig drog. I ett tredje steg genomfördes en multivariat logistisk regressionsanalys för att testa huruvida skillnader i önskemål om hjälp beroende på huvudsaklig drog kvarstår efter kontroll för bostadssituation, typ av inkomst samt prostitution. ${ }^{12}$ Resultaten från den logistiska regressionsanalysen redovisas i tabell fyra.

Resultatet av det första analyssteget visade att osäker boendesituation (bostadslös, härbärge, inneboende), illegal inkomst samt erfarenhet av att sälja sex hade ett positivt signifikant samband med

12 Den beroende variabeln, önskemål om hjälp, har kodats som $1=$ önskar hjälp och $0=$ önskar ej hjälp. De oberoende variablerna har kodats enligt följande. Huvuddrog: $1=$ heroin och $0=$ amfetamin. Bostadssituation: $1=$ osäkert boende och $0=$ tryggt boende. Inkomst: $1=$ illegal inkomst och $0=$ ingen illegal inkomst. Prostitution: $1=$ har sålt sex och $0=$ har ej sålt sex. Ålder varierar mellan 20 och 66 år. önskemål om hjälp. Däremot förelåg inget samband mellan ålder och önskemål om hjälp. Resultatet av det andra analyssteget visade att osäker bostadssituation samt erfarenhet av att sälja sex hade ett positivt signifikant samband med önskemål om hjälp, även efter kontroll för huvudsaklig drog. Resultatet av det tredje analyssteget visade att huvudsaklig drog var den faktor som har störst enskild betydelse för önskemål om hjälp, där oddsen för att önska hjälp var betydligt högre för dem med heroin som huvuddrog, i jämförelse med dem med amfetamin som sin huvuddrog. Heroin som huvuddrog var också den enda variabel i denna modell som visade ett signifikant positivt samband med önskemål om hjälp.

Flera olika faktorer verkar således ha betydelse för om individen önskar hjälp eller inte. Framförallt verkar heroin som huvuddrog, osäker bostadssituation samt erfarenhet av att sälja sex, vara faktorer vilka bidrar till ett ökat intresse för hjälp från samhället.

\section{Tabell 4.}

Logistisk regressionsanalys för önskemål om hjälp, steg 1, 2 och 3

\begin{tabular}{|c|c|c|c|c|c|c|c|c|}
\hline & \multicolumn{4}{|c|}{ Steg I } & \multicolumn{3}{|c|}{ Steg 2} & \multirow{2}{*}{$\begin{array}{c}\text { Steg } 3 \\
\text { OR }\end{array}$} \\
\hline & OR & OR & OR & OR & OR & OR & OR & \\
\hline Ålder & 0,968 & & & & & & & \\
\hline Osäkert boende & & $3,443^{*}$ & & & $4,378^{* * *}$ & & & 3,010 \\
\hline Illegal inkomst & & & $3,747^{* *}$ & & & 1,938 & & 1,279 \\
\hline Sålt sex & & & & $5,774^{* * * *}$ & & & $2,909^{*}$ & 1,660 \\
\hline Heroin & & & & & $15,820^{* * * *}$ & $10,279 * * *$ & $7,620 * * *$ & 12,964 **** \\
\hline Cox \& Snell R ${ }^{2}$ & 0,022 & 0,053 & 0,078 & 0,110 & 0,287 & 0,220 & 0,214 & 0,303 \\
\hline
\end{tabular}

Signifikans: ${ }^{*} \mathrm{p}<0,05{ }^{* *} \mathrm{p}<0,01{ }^{* * *} \mathrm{p}<0,001$

Richert, Månsson \& Laanemets: Kvinnor som injicerar heroin respektive amfetamin. 


\section{Diskussion}

Resultatet visar på flera tydliga skillnader beroende på vilken drog kvinnorna huvudsakligen använder vad gäller social situation, kontakter med myndigheter och organisationer, erfarenhet av missbruksbehandling samt önskemål om hjälp.

Vad gäller social situation framkom skillnader mellan de två grupperna, vilka tyder på varierande grad av delaktighet i majoritetssamhället (social integrering) respektive involvering $i$ en narkoman subkultur (social marginalisering). En större andel amfetaminanvändare har både egen bostad och endast legala/formella inkomster, medan en större andel heroinanvändare både har en mycket osäker bostadssituation och uteslutande illegala/informella inkomster från langning, prostitution eller stölder. Detta tyder på att en större grupp amfetaminanvändare kan beskrivas som "socialt integrerade", medan en större grupp heroinanvändare kan beskrivas som "socialt marginaliserade". Denna skillnad har även påvisats i en tidigare studie av sprutbytesprogrammets besökare (Stenström \& Örnberg 1995).

Liksom i flera tidigare studier av injektionsmissbrukande kvinnor (se t.ex. Paone m.fl. 1995, 1999, Bretteville-Jensen 1996, 2005), var erfarenhet av att sälja sex relativt vanligt i den undersökta gruppen. Erfarenhet av att sälja sex var betydligt vanligare bland kvinnor med heroin som huvudsaklig drog. De amfetaminanvändare som någon gång sålt sex har dock en tidigare prostitutionsdebut och en något större utsatthet för prostitutionsrelaterade våldshandlingar, i jämförelse med motsvarande grupp heroi- nanvändare. Trots detta har amfetaminanvändare med erfarenhet av att sälja sex i mindre utsträckning, än heroinanvändare med erfarenhet av att sälja sex, haft kontakt med någon myndighet/organisation som kan hjälpa dem med prostitutionsrelaterad problematik.

En större andel kvinnor med erfarenhet av prostitution hade någon gång varit $\mathrm{i}$ behandling för sitt missbruk och en större andel uppgav att de önskade någon typ av hjälp från samhället. Detta resultat skiljer sig från tidigare studier, vilka snarare har visat på svårigheter att nå just denna grupp (se t.ex. Kurtz m.fl. 2005, Weiner 1996). Möjligen beror detta delvis på att man i Malmöregionen har flera insatser som vänder sig till kvinnor med prostitutionserfarenhet (t.ex. Navet och prostitutionsgruppen).

Kvinnor med heroin som huvudsaklig drog hade i betydligt större utsträckning varit i kontakt med olika myndigheter och organisationer det senaste året, i större utsträckning behandlats för sitt missbruk någon gång, behandlats det senaste året, behandlats vid flera tillfällen samt någon gång självmedicinerat. Heroinanvändarna uppgav också i större utsträckning att de för närvarande hade bra hjälp från samhället eller att de önskade någon typ av hjälp för att förändra sin situation.

Dessa skillnader kan ha flera förklaringar. En trolig förklaring är att detta är ett uttryck för ett större vårdbehov bland kvinnor med heroin som huvudsaklig drog. Med anledning av att heroinmissbrukare visat sig ha ett mer varaktigt missbruk och betydligt färre perioder med ett mindre omfattande drogbruk (Hser m.fl. 2008) 
samt en högre grad av beroende (Kaye \& Darke 2000, Gossop m.fl. 1992, Anthony m.fl. 1994, Darke \& Hall 1995), är det rimligt att tänka sig att denna grupp har större erfarenhet av missbruksbehandling och ett större aktuellt behov av vård och behandling för sitt missbruk. Även om data kring frekvens eller varaktighet i missbruk eller grad av beroende saknas för den studerade gruppen finns vissa indikationer kring detta. En större andel amfetaminanvändare uppgav t.ex. att de periodvis klarat av att avsluta sitt missbruk utan hjälp av andra droger eller läkemedel och ett antal amfetaminanvändare beskrev att deras drogbruk i dagsläget inte utgjorde ett problem för dem. Även det faktum att heroinanvändarna framförallt önskar hjälp med behandling för sitt missbruk, medan amfetaminanvändarna i lika stor utsträckning önskar annan typ av hjälp (boende och förstående från samhället), tyder på att heroinanvändarna framförallt har ett större vårdbehov relaterat till sitt missbruk.

En annan möjlig förklaring till skillnader i kontakt med myndigheter, tidigare erfarenhet av behandling samt aktuella önskemål om hjälp kan ha att göra med skillnader i socialarbetares bedömningar av vårdbehov beroende på huvuddrog samt på skillnader i vård- och behandlingsutbud för de två grupperna. Att färre amfetaminanvändare har varit i kontakt med myndigheter eller behandlats för sitt missbruk kan bero på att de i mindre utsträckning erbjuds stöd och behandling. Mycket tyder på att den senaste tidens utveckling inom missbruksvården, med en ökad ambition att få in fler heroinanvändare i behandling, samtidigt inneburit ett minskat antal behandlings- platser för amfetaminanvändare (Svensson 2009).

Wallander och Blomqvist (2009) visar i sin vinjettstudie på stora skillnader i socialarbetares bedömningar av lämplig behandlingsform, beroende på om klienten, i beskrivningen som bedömdes, huvudsakligen använde heroin eller amfetamin. Oddsen för att bli rekommenderad slutenvårdsbehandling var betydligt större för heroinanvändare i jämförelse med amfetaminanvändare, också när kontroll hölls för klienternas sociala situation och deras fysiska och psykiska hälsa (Wallander \& Blomqvist 2009). Dessutom finns indikationer på att amfetaminanvändares vårdbehov i vissa fall möts med fängelse i stället för missbruksbehandling (Håkansson 2009). I dagsläget saknas också evidensbaserade behandlingsalternativ för amfetaminmissbrukare (SBU 2001) samtidigt som det finns fler och mer självklara behandlingsalternativ för heroinanvändare. ${ }^{13}$ I Malmö finns t.ex. flera behandlingsinstitutioner vilka framförallt vänder sig till heroinmissbrukare (t.ex. Navet och Beroendecentrum).

Bristen på lämpliga stöd- och behandlingsinsatser för amfetaminanvändare är också något som återspeglas i intervjupersonernas kommentarer. Flera amfetaminanvändare har uppgivit som anledning till att

13 Detta innebär dock inte nödvändigtvis att det saknas bra behandlingsformer för amfetaminanvändare. Det faktum att de i dagsläget tillgängliga behandlingsformerna för amfetaminanvändare saknar evidens skulle dock kunna medföra en mindre benägenhet från tjänstemän att bevilja behandling.

Richert, Månsson \& Laanemets: Kvinnor som injicerar heroin respektive amfetamin. 
de inte önskar någon hjälp, att samhället inte kan göra något för dem, att de när de efterfrågar hjälp, ändå inte får någon, eller att de blir stjälpta snarare än hjälpta av de insatser som erbjuds.

Även andra faktorer än huvudsaklig drog visade sig ha betydelse för önskemål om hjälp. Otrygg bostadssituation samt erfarenhet av att sälja sex var faktorer som visade sig ha ett signifikant positivt samband med önskemål om hjälp, även efter kontroll för huvuddrog. Kvinnor med en otrygg bostadssituation och/eller med erfarenhet av prostitution kan därför generellt antas ha ett större intresse av hjälp från samhället, oavsett om de huvudsakligen injicerar heroin eller amfetamin.

Att majoriteten av kvinnorna önskar specifika behandlingsinsatser där enbart kvinnor tas emot, kan bero på att man då anser sig ha bättre möjligheter att få sina behov tillgodosedda. Det skulle också kunna vara ett uttryck för tidigare negativa erfarenheter av könsblandad behandling, men också av dåliga erfarenheter i kontakten med missbrukande män eller manliga sexköpare. Att kvinnor upplever vissa fördelar med att delta i behandling enbart tillsammans med andra kvinnor, har tidigare uppmärksammats (se t.ex. Trulsson 2003, Christensen 1996).

Det faktum att en så stor andel av de besökande kvinnorna valt att delta i studien, och det faktum att den övervägande majoriteten av dessa kvinnor valde att uttrycka och specificera önskemål om hjälp är ett viktigt resultat i sig. En trolig förklaring till den höga svarsfrekvensen är, som tidigare nämnts, besökarnas ofta nära och långvariga kontakt med persona- len på sprutbytet samt deras positiva syn på verksamheten. Detta, tillsammans med verksamhetens breda kontaktyta med individer med ett aktivt injektionsmissbruk, visar på sprutbytesprogrammets stora potential som forsknings- och kunskapsbas.

\section{Implikationer för svensk narkomanvård}

Att en så stor andel injektionsmissbrukande kvinnor som önskar någon typ av hjälp för att förändra sin situation, inte får denna hjälp, är anmärkningsvärt. En viktig utgångspunkt bör vara att ta kvinnornas önskemål om hjälp på stort allvar och i största mån underlätta för att de skall kunna realiseras.

Kvinnor som injicerar heroin verkar generellt uppleva ett stort vårdbehov och visa ett stort intresse av hjälp från samhället. Då dessa kvinnor framförallt önskar större möjlighet till underhållsbehandling för sitt heroinmissbruk, bör ett viktigt mål vara att utöka antalet platser och öka tillgängligheten till denna behandlingsform.

Det blir också viktigt att utveckla framgångsrika och attraktiva behandlingsalternativ, även för amfetaminanvändare, eftersom detta till stor del saknas i dagsläget. Det blir även viktigt att satsa resurser på att förbättra deras livssituation, då majoriteten inte primärt önskar hjälp med att förändra sitt missbruk. Vissa grupper amfetaminanvändare, framförallt de med erfarenhet av prostitution samt de som saknar tryggt boende, verkar i likhet med heroinanvändarna ge uttryck för ett stort 
behov av hjälp, varför dessa individer bör tillhöra prioriterade målgrupper.

Kvinnornas önskemål om tillgång till specifika behandlingsinsatser/avdelningar där enbart kvinnor tas emot är något som borde undersökas närmare och något som borde övervägas inom befintliga behandlingsverksamheter och vid utformandet av nya behandlingsformer.

\section{Referenser}

Aceijas, C., Friedman, S.R., Cooper, H.L.F., Wiessing, L., Stimson, G.V. \& Hickman, M. (2006) Estimates of Injecting drug users at the national and local level in developing and transitional countries, and gender and age distribution. Sexually Transmitted Infections, vol. 82 (Supplement) nr. 3, s.10-17.

Angelin, D., Hser, Y. \& McGlothin, W. (1987) Sex differences in addiction careers. American Journal of Drug and Alcohol Abuse, vol. 15, nr. 1-2, s. 59-71.

Anthony, J.C., Warner, L.A. \& Kessler, R.C. (1994) Comparative epidemiology of dependence on tobacco, alcohol, controlled substances, and inhalants: basic findings from the National Comorbidity Survey. Experimental and Clinical Psychopharmacology, vol. 2, nr. 3, s. 244268.

Bergmark, A., Björling, B., Grönbladh, L., Olsson, B., Oscarsson, L., \& Segraeus, V. (1994) Klienter $i$ institutionell narkomanvård ( $\mathrm{Nr} 66)$. Stockholm: Institutionen för socialt arbete, Stockholms universitet.

Bourgois, P., Prince, B., \& Moss, A. (2004) The everyday violence of hepatitis $\mathrm{C}$ among young women in who inject drugs in San Francisco. Human Organization, vol. 63, nr. 3, s. 253-264.

Bretteville-Jensens, A.L. \& Sutton, M. (1996) The income-generating behaviour of injecting drugusers in Oslo. Addiction, vol. 91 nr. 1, s. 63-79.

Bretteville-Jensen, A.L. (2005) Økonomiske aspekter ved sprøytemisbrukeres forbruk av ulovlige rusmidler. En analyse av intervjuer foretatt 1993-2004. Oslo: SIRUS rapport nr. 4.

Byqvist, S. (1997) Svenska narkotikamissbrukande kvinnor och män. Missbruksförlopp och kriminalitet. Rapport i socialt arbete nr 84. Stockholm: Institutionen för socialt arbete, Stockholms universitet.

Byqvist, S. (2005) Narkotikamissbrukande kvin nor i Sverige. Marginalisering och social belast ning. Könsskillnader. Stockholm: Mobilisering Mot Narkotika.

CAN (2006) Drogutvecklingen i Sverige 2006. Rapport nr 98. Stockholm: Centralförbundet för alkohol-och narkotikaupplysning.

Christensen, A (1996) Jenter som kommer og jenter som går. Oslo: Statens institut for alkohol-og narkotikaforskning, SIFA rapport 6/96.

Dalla, R.L., Xia, Y. \& Kennedy, H. (2003) "You just Give them what they Want and Pray they don't Kill You". Street-Level Sex Workers' Reports of Victimization, Personal Resources, and Coping Strategies, Violence Against Women, vol. 9, nr. 11, s. 1367-1394.

Darke, S. \& Hall, W. (1995) Levels and correlates of polydrug use among heroin users and regular amphetamine users. Drug and Alcohol Dependence, vol. 39, nr. 3, s. 231-235.

ECNN (2002) Fokus på narkotika. Injektionsmissbruk utgör en utmaning för folkhälsopolitiken. Briefing nr 4, 2002. Tillgänglig (2011-02-20): http://www.emcdda.europa.eu/attachements. cfm/att_33486_SV_Dif04sv.pdf

Richert, Månsson \& Laanemets: Kvinnor som injicerar heroin respektive amfetamin. 
EMCDDA (2001) Injecting drug use, risk behaviour and qualitative research in the time of AIDS. Insights seiries nr. 4, 2001.

Gossop, M., Griffiths, P., Powis, B. \& Strang, J. (1992) Severity of dependence and route of administration of heroin, cocaine and amphetamines. British Journal of Addiction, vol. 87, nr. 11, s. 1527-1536.

Hall, W., Darke, S., Ross, M. \& Wodak, A. (1993) Patterns of drug use and risk-taking among injecting amphetamine and opioid drug users in Sydney, Australia. Addiction, vol. 88, nr. 4, s. 509-516.

Heilig, M. (2004) Beroendetillstånd. Lund: Studentlitteratur.

Holmberg, C., Smirthwaite, A. \& Nilsson, A. (2005) Mäns våld mot missbrukande kvinnor, ett kvinnofridsbrott bland andra. Stockholm: Mobilisering Mot Narkotika, rapport $\mathrm{nr} 8$, 2005.

Hser, Y. I., Huang, D., Brecht, M. L., Li, L. \& Evans, E. (2008) Contrasting trajectories of heroin, cocaine, and methamphetamine use. Journal of Addictive Diseases, vol. 27, nr. 3, s. 13-21.

Håkansson, A. (2009) Overdoses, Suicidal Behaviour and Clinical Characteristics in Heavy Drug Users. Studies in the Criminal Justice System. Lund: Lund University.

Kaye, S. \& Darke, S. (2000) A comparison of the harms associated with the injection of heroin and amphetamines. Drug and Alcohol Dependence, vol. 58, nr. 1-2, s. 189-195.

Kurtz, S.P., Surratt, H.L., Inciardi, J. A. \& Kiley, M. C. (2004) Sex Work and "Date" Violence. Violence Against Women, Vol. 10, nr. 4, s. 357-385

Kurtz, S.P., Surratt, H.L., Inciardi, J. A. \& Kiley, M. C. (2005) Barriers to Health and Social Services for Street-Based Sex Workers. Journal of Health Care for the poor and Underserved, vol. 16, nr. 2, s. 345-361.

Laanemets, L. (2007) Navet. Om kvinnor, prostitution, metadon- och Subutexbehandling. Stockholm: Mobilisering Mot Narkotika.

Lander, I., Olsson, B., Rönneling, A. \& Skrinjar, M. (2002) Narkotikamissbruk och marginalisering. MAX-projektet, slutrapport. Stockholm:
Centralförbundet för alkohol- och narkotikaupplysning.

Lander, I. (2003) Den flygande maran. En studie om åtta narkotikamissbrukande kvinnor $i$ Stockholm. Stockholm: Kriminologiska Institutionen, Stockholms universitet.

McKetin, R., Kelly, E. \& Indig, D. (2005) Characteristics of treatment provided for amphetamine use in New South Wales, Australia. Drug and Alcohol Review, vol. 24, nr 5, s. 433-436.

Olsson, B., Adamsson, W.C. \& Byqvist, S. (2001) Det tunga narkotikamissbrukets omfattning i Sverige 1998. MAX-projektet, delrapport 3. Stockholm: Centralförbundet för alkohol- och narkotikaupplysning, rapport nr. 61 .

Palmberg, K., Lundberg, L. (2009) Verksamhetsberättelse för prostitutionsgruppen i Malmö 2008. Malmö: Sociala Resursförvaltningen.

Paone, D., Caloir, S., Shi, Q., \& Des Jarlais, D. C. (1995) Sex, drugs, and syringe exchange in New York city: women's experiences. Journal of American Medical Women's Association, vol. 50, nr. 3-4, s. 109-114.

Paone, D., Cooper, H., Alperen, J., Shi, Q. \& Des Jarlais, D. C. (1999) HIV risk behaviors of current sex workers attending syringe exchange: the experience of women in five cities. AIDS Care, vol. 11, nr. 3, s. 269-280.

Pates, R., McBride, A. \& Arnold, K. (Eds) (2005). Injecting Illicit Drugs. Oxford: Blackwell Publisching Ltd.

Richert, T. (2009). Injektionsmissbrukande kvinnors inkomstkällor och anskaffning av droger. Nordisk Alkohol- och Narkotikatidskrift, vol. 26, nr. 5, s. 365-383.

Rosenbaum, M. (1981) Women on heroin. New Brunswick: Rutgers University Press.

Rönnberg, S., Andrén, A., Hermansson, U., Stenström, N. \& Öberg, D. (1992) Sprutbyte för personer med intravenöst missbruk. Stockholm: Institutionen för socialt arbete.

SBU (2001) Behandling av alkohol och narkotikaproblem. En evidensbaserad kunskapssammanställning. Vol. 1 \& 2. (nr 156/1, 156/11), Stockholm: SBU.

Socialstyrelsen (2004) Läkemedelsassisterad 
behandling av heroinmissbrukare. En kunskapsöversikt. Tillgänglig (2010-11-02): http://www.socialstyrelsen.se/publikationer2004/2004-110-11

Srisurapanont, M., Jarusuraisin, N. \& Kittirattanapaiboon, P. (2001a) Treatment for amphetamine withdrawal. Cochrane Database of Systematic Review, nr. 4.

Srisurapanont, M., Jarusuraisin, N. \& Kittirattanapaiboon, P. (2001b) Treatment for amphetamine dependence and abuse. Cochrane Database of Systematic Review, nr. 4.

Stafström, M. \& Norén, A. (2005) Skåne-UNO 2004 - En kartläggning av narkotikamissbrukets omfattning. Länsstyrelsens i Skåne län och Skånesamverkan mot droger. Rapportserien Skåne i utveckling: Rapport 6, 2005.

Stenström, N. (2008) Sprutbyte vid intravenöst narkotikamissbruk. En longitudinell studie av deltagarna i sprutbytesprogrammet i Malmö. Sundsvall: Mittuniversitetet.

Stenström, N. \& Öberg, D. (1995) Socialt integrerade och utslagna intravenösa narkotikamissbrukare. En studie av deltagare i sprutby- tesprogrammet vid infektionskliniken, Malmö allmänna sjukhus. Stockholm: Institutionen för socialt arbete - socialhögskolan, Stockholms universitet.

Svensson, B. (2009) Problem amphetamine and methamphetamine use in Sweden, related consequences and responses. Malmö: Malmö högskola.

Trulsson, K. (2003) Konturer av ett kvinnligt fält. Om missbrukande kvinnors möten i familjeliv och behandling. Lund: Socialhögskolan.

Tunving, K. (1986). Careers in alcoholism and drug addiction. Clinical and epidemiological studies. Lund: Lunds Universitet.

Wallander, L. \& Blomqvist, J. (2009) Modeling Ideal Treatment Recommendations: A Factorial Survey of Swedish Social Workers' Ideal Recommendations of Inpatient or Outpatient Treatment for Problem Substance Users. Journal of Social Service Research, vol 35, s 47-64.

Weiner, A. (1996) Understanding the social needs of streetwalking prostitutes. Social Work, vol. 41, nr. 1, s. 97-105.

\section{Summary}

\section{Women Who Inject Heroin or Amphetamines Differences in Life Situation, History of Treatment and Request for Help}

The purpose of this paper is to investigate differences between women who inject heroin and women who inject amphetamines, particularly as regards their life situation, treatment history and current request for help. The results are based on standardized interviews with 188 women at the needle exchange programme in Malmö.
A larger proportion of amphetamine users had stable housing combined with exclusively legal/formal sources of incomes (wage labour, pension, social benefits), whereas a larger proportion of heroin users had unstable housing combined with illegal/informal sources of income (prostitution, dealing, theft). This implicates that

Richert, Månsson \& Laanemets: Kvinnor som injicerar heroin respektive amfetamin. 
amphetamine users, in general, are more socially included whereas heroin users are more marginalized.

Women with heroin as their principal drug reported to a higher extent experiences of all types of treatment, lifetime history of treatment, treatment on several different occasions and contact with the social services and outreach groups during the last year.

Several factors were significantly related to a request for help, whereas heroin as principal drug was the single factor showing a significant positive relation to request for help in a multivariate logistic regression equation.

The differences between the two groups as regards their history of treatment and present requests for help may have several explanations. One probable explanation has to do with different levels of abuse and dependence in the two groups, where heroin users, due to a higher level of dependence, have a greater demand for care and treatment. A second explanation concerns differences in treatment supplies available for the two groups. To this day there is no evidence-based treatment for amphetamine abuse. Treatment options for heroin abuse, on the other hand, are well documented and well recognized, and heroin users are a prioritized group for interventions within the Swedish care system. 